\title{
DIRECT CORONARY ARTERY PERFUSION FROM THE LEFT VENTRICLE
}

Kotaro Suehiro, MD

Juichiro Shimizu, MD, $\mathrm{PhD}^{\mathrm{b}}$

Geng-Hua Yi, MD

Shu-Ming Zhu, MD

Anguo $\mathrm{Gu}, \mathrm{MD}^{\mathrm{b}}$

Robert R. Sciacca, Eng ScD ${ }^{\mathrm{b}}$

Jie Wang, MD, PhD ${ }^{\mathrm{b}}$

Daniel Burkhoff, $\mathrm{MD}, \mathrm{PhD}^{\mathrm{b}}$
Objectives: Trends in coronary bypass surgery require less invasive techniques and more conduits. We investigated the ability of direct coronary perfusion from the left ventricle to support regional and global cardiac function.

Methods: A conduit was established between the left ventricle and left anterior descending coronary artery $(n=6)$ with an interposed Starling resistor that allowed for graded regulation of backward flow. Changes of coronary flow, regional function in the territory of the left anterior descending coronary artery, and reactive hyperemia were studied. In 3 separate dogs, functional tolerance to increased heart rate was tested. In another $3 \mathrm{dogs}$, left ventricle-left anterior descending and left ventricle-left circumflex coronary artery conduits were established simultaneously (double conduit), and global function was tested.

Results: Without flow regulation, flow through the left ventricle-left anterior descending conduit exhibited high peaking (102 $\pm 35 \mathrm{~mL} / \mathrm{min})$, midsystolic forward flow, and large pandiastolic backward flow (peaking at $-47 \pm 22 \mathrm{~mL} / \mathrm{min}$ ). Mean coronary flow and regional function were maintained at $46.0 \% \pm 7.1 \%(35.8 \%-54.2 \%)$ and $45.3 \% \pm 29.1 \%(-1.8 \%$ $74.2 \%$ ) of their respective normal values. When the Starling resistor was used to regulate backward flow, these values increased to $70.8 \% \pm 12.5 \%$ $(56.8 \%-90.4 \%)$ and $70.2 \% \pm 27.8 \%(23.6 \%-107.7 \%)$, respectively. Coronary and functional reserve with a left ventricle-left anterior descending conduit were not observed. With the double conduit, global ventricular contractility indexed by end-systolic pressure-volume relation averaged $46 \% \pm 35 \%$ of its normal value.

Conclusions: A left ventricle-coronary artery conduit supplied approximately $45 \%$ of normal blood flow and regional function, and both were improved by regulation of backward flow. Therefore, a conduit from the left ventricle to an epicardial vessel could serve as a rapidly deployable means of revascularizing totally occluded coronary vessels for which suitable natural conduits are not available. (J Thorac Cardiovasc Surg 2001;121:307-15)
From the Departments of Surgery ${ }^{\mathrm{a}}$ and Medicine, ${ }^{\mathrm{b}}$ Columbia University, New York City, NY.

This work was supported by a research grant from Percardia Inc, Nashua, NH.

Received for publication July 20, 2000; revisions requested Aug 30, 2000; revisions received Sept 18, 2000; accepted for publication Sept 19, 2000.

Address for reprints: Daniel Burkhoff, MD, PhD, 177 Fort Washington Ave, MHB 5-435, New York, NY 10032 (E-mail: db59@columbia.edu).

Copyright (C) 2001 by The American Association for Thoracic Surgery

$0022-5223 / 2001 \$ 35.00+0 \quad \mathbf{1 2 / 1 / 1 1 1 9 6 8}$

doi: $10.1067 /$ mtc. 2001.111968
D ecently, interest has resurfaced in development of R alternative coronary revascularization techniques. One proposed technique is to use an artificial conduit whose distal end is inserted into the vessel and whose proximal end is inserted transmyocardially directly into the left ventricle (LV). ${ }^{1,2}$ Such a device could be deployed through a minimally invasive approach on a beating heart, for example, in patients with a calcified aortic root or in redo operations where suitable graft material is lacking. However, without a valve inside a ventricle-coronary artery conduit, backflow drainage during diastole resulting in decreased mean forward flows is predicted. 


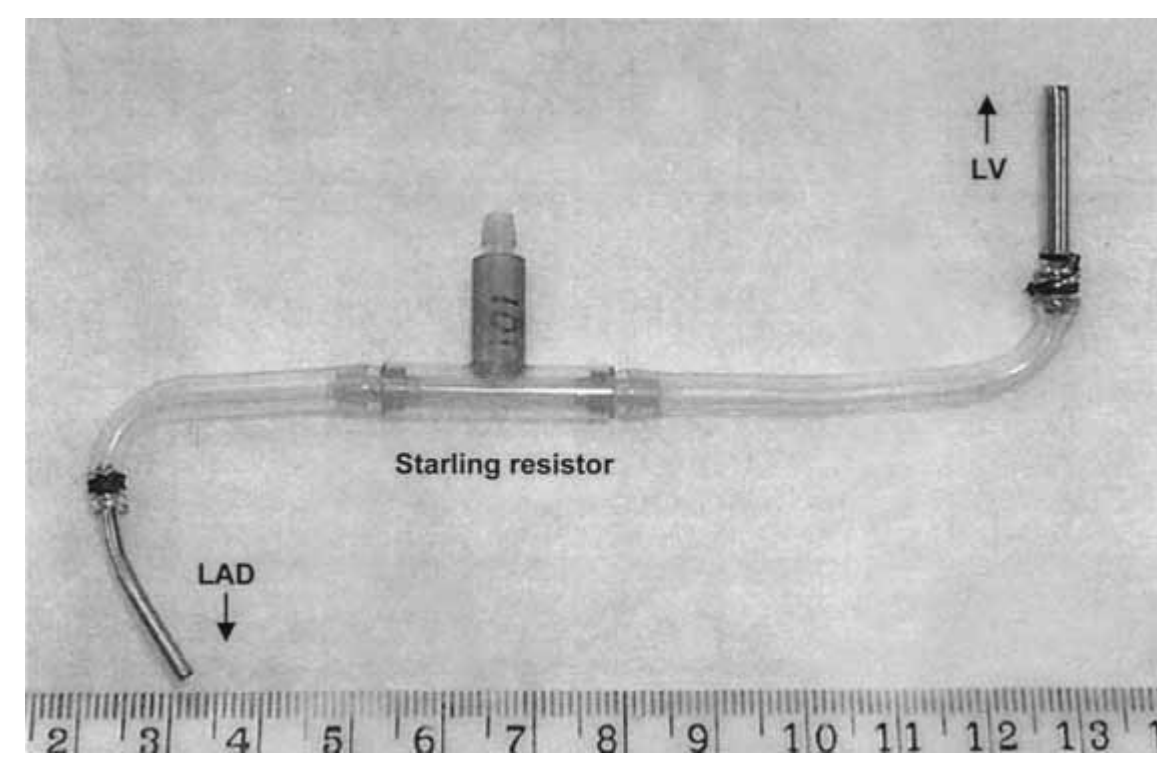

Fig 1. The left ventricle-coronary artery conduit system. The Starling flow resistor ${ }^{3}$ has a thin-walled, collapsible polyvinyl chloride inner tube (2-mm internal diameter, the "lumen") inside an airtight $\mathrm{T}$ tube that can be pressurized to a desired compression pressure $\left(\mathrm{P}_{\text {Starling }}\right)$. When pressure inside the lumen falls below $\mathrm{P}_{\text {Starling }}$, the lumen collapses, acting as a valve. The dead volume of the entire tubing system was $0.95 \mathrm{~mL}$. $L V$, Left ventricle; $L A D$, left anterior descending coronary artery.

The purpose of this study was to elucidate the physiology of blood flow through a direct LV-coronary artery conduit, including the ability of that flow to maintain regional and global myocardial function, and to determine the degree to which impeding backward flow through the conduit provides more effective perfusion.

\section{Methods}

Studies were performed in compliance with the "Guide for the Care and Use of Laboratory Animals" prepared by the Institute of Laboratory Animal Resources, National Research Council, and published by the National Academy Press, revised 1996.

LV-coronary artery conduit. A system was established to create a conduit between the LV and the left anterior descending coronary artery (LAD). An LAD perfusion cannula (internal diameter of $\sim 1.8 \mathrm{~mm}$ ) and an LV cannula (internal diameter of $\sim 2.5 \mathrm{~mm}$ ) were connected with a Starling flow resistor and polyvinyl chloride tubing (Fig 1). The Starling flow resistor $^{3}$ has a thin-walled, collapsible polyvinyl chloride inner tube (2-mm internal diameter, the "lumen") inside an airtight $\mathrm{T}$ tube that can be pressurized to a desired compression pressure $\left(\mathrm{P}_{\text {Starling }}\right)$. When pressure inside the lumen falls below $\mathrm{P}_{\text {Starling }}$ the lumen collapses, acting as a valve. The dead volume of the entire tubing system was $0.95 \mathrm{~mL}$.

Surgical preparations. Twelve adult mongrel dogs, weighing 27 to $32 \mathrm{~kg}$, were used in this study. Each dog was anesthetized with sodium pentobarbital $(30 \mathrm{mg} / \mathrm{kg}$ intravenously) and ventilated. A conductance catheter with a
Mikro-Tip manometer (Millar Instruments, Inc, Houston, Tex) was inserted into the LV through the right carotid artery to measure LV pressure and volume. The left fifth intercostal space was then entered. The proximal part of the LAD was dissected for later cannulation. The more distal portion of the LAD was dissected and an ultrasonic flow probe (Transonic Systems Inc, Ithaca, NY) was placed. A pair of ultrasonic crystals was placed in the region supplied by the blood flow through the conduit and was connected to a sonomicrometer (Triton Technology, Inc, San Diego, Calif) to monitor segment shortening. So that blood flow to the tested region would be derived predominantly from the LAD, all visible collateral vessels to the LAD were ligated.

The dog was then heparinized (10,000 U intravenously). The LV cannula was inserted through the anterior wall and the proximal LAD was ligated. The coronary perfusion cannula was introduced into the LAD after an arteriotomy, which thus established the LV-LAD conduit. The myocardial ischemic time was no more than 2 minutes.

In the 3 separate double shunt studies (see below), a second conduit was established from the LV to the left circumflex coronary artery (LCx).

\section{Protocol}

Coronary flow and regional function. LAD flow and regional function were assessed in 6 animals. Baseline measurements were performed before the $\mathrm{LAD}$ was cannulated. The LV-LAD conduit was then established and $\mathrm{P}_{\text {Starling }}$, initially set at $0 \mathrm{~mm} \mathrm{Hg}$, was increased stepwise by increments of 20 to $30 \mathrm{~mm} \mathrm{Hg}$ until blood flow through the conduit was 

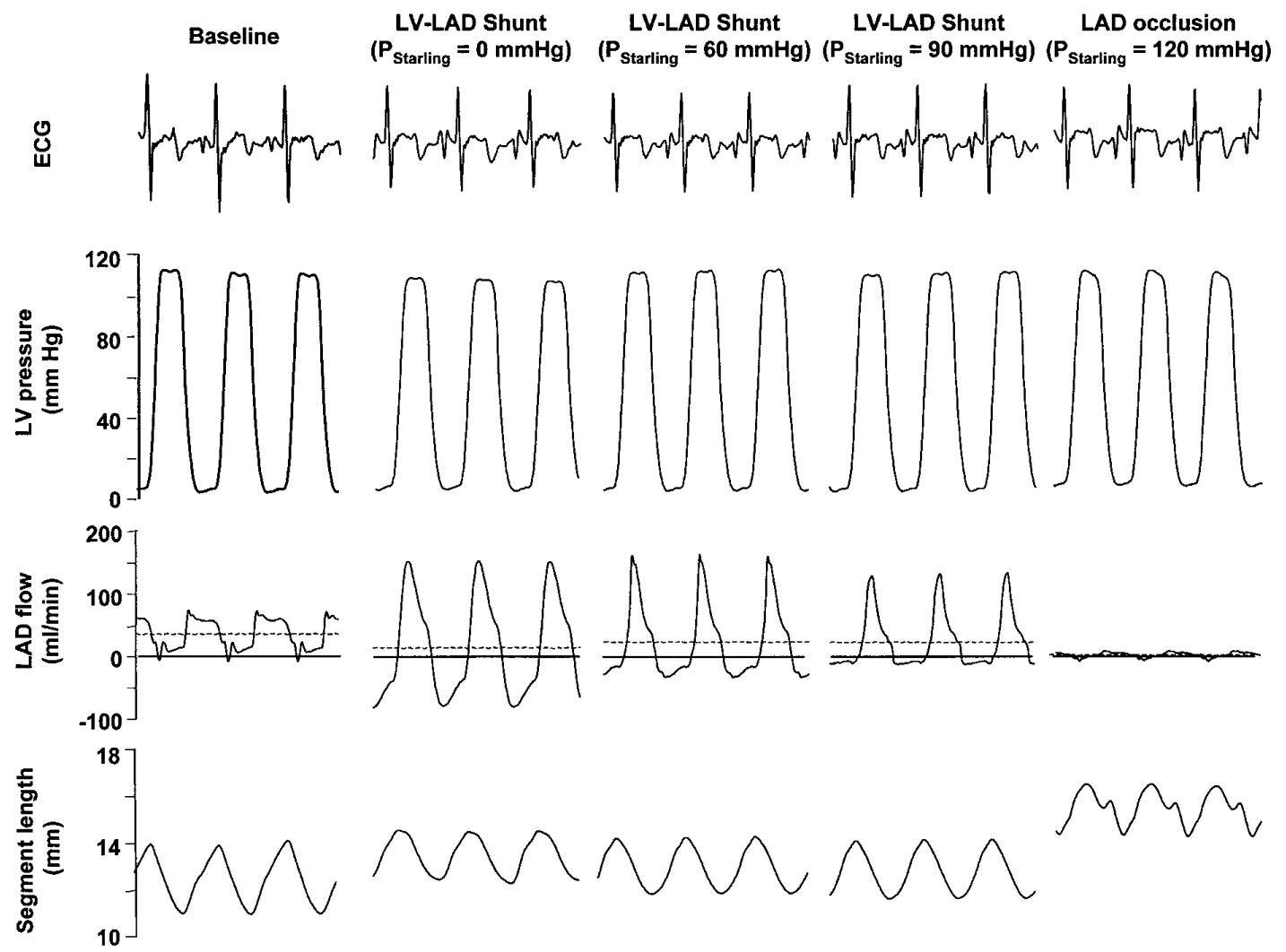

Fig 2. Representative recordings of hemodynamics at various settings of $\mathrm{P}_{\text {Starling }}$, the compression pressure in the Starling flow resistor. See text for detailed description of findings. $L V$, Left ventricle; $L A D$, left anterior descending coronary artery.

totally obstructed. At each level of $\mathrm{P}_{\text {Starling }}, 2$ minutes were allowed for establishment of stable hemodynamic conditions, at which time physiologic measurements were made.

Regional blood flow. In the same dogs, regional myocardial blood flow was measured under 4 conditions with the use of colored microspheres as described by Kowallik and associates. ${ }^{4}$ First, baseline measurements were obtained before LAD cannulation. During coronary perfusion through the conduit, regional blood flow was assessed at a $\mathrm{P}_{\text {Starling }}$ of 0 $\mathrm{mm} \mathrm{Hg}$, at a $\mathrm{P}_{\text {Starling }}$ that provided maximum total mean epicardial coronary artery flow, and finally with total occlusion of the conduit.

Reactive hyperemia. Blood flow after release of a 2-minute LAD occlusion (reactive hyperemia) before and after LVLAD conduit placement was assessed in the same 6 dogs. After reperfusion, coronary flow and regional function were recorded every 20 seconds until each returned to its preocclusion value.

Coronary and functional reserve during tachycardia. In 3 dogs, the ability of the conduit without flow regulation to provide sufficient flow to maintain myocardial function at higher heart rates was assessed. Propranolol (0.1-0.2 mg/kg intravenously) was administered to decrease sinus rate to approximately $100 \mathrm{~min}^{-1}$ and heart rate was then increased at $20-\mathrm{min}^{-1}$ steps to a maximum of $160 \mathrm{~min}^{-1}$. The heart was paced for 2 minutes at each rate.

Global function during double conduit studies. In 3 dogs, pressure-volume loops were recorded with inferior vena caval occlusions ${ }^{5}$ before the operation (baseline), after placement of the LV-LAD conduit (single conduit), and after placement of the LV-LCx conduit (double conduit). Parallel conductance was determined by the hypertonic saline technique. ${ }^{6}$

Data analysis. In each experiment, except double conduit studies, LAD flow, segmental shortening, and LV pressure were measured. In double conduit studies, LV pressure and volume, LAD blood flow, and LCx blood flow were measured. All data were digitized at $200 \mathrm{~Hz}$ and analyzed offline. As an index of regional LV systolic function, regional stroke work (the pressure-segment length loop area) divided by end-diastolic segment length was used. End-systolic pressure-volume relationships (ESPVRs) were determined from the family of pressure-volume loops in the double conduit studies. $^{7}$

Statistics. All data are presented as means and standard deviations. Statistical comparisons were performed with repeated-measures analysis of variance with Bonferroni correction. Linear ESPVRs were compared with analysis of covariance. 
Table I. Comparison of LV-LAD conduit flow and normal LAD flow

\begin{tabular}{lccc}
\hline & $\begin{array}{c}\text { Baseline } \\
(\text { normal })\end{array}$ & $\begin{array}{c}\text { LV-LAD conduit } \\
\left(P_{\text {Starling }}=0 \text { mm Hg) }\right.\end{array}$ & $\begin{array}{c}\text { LV-LAD conduit } \\
\text { (maximum mean flow) }\end{array}$ \\
\hline Heart rate $\left(\mathrm{min}^{-1}\right)$ & $134 \pm 12$ & $131 \pm 10$ & $133 \pm 16$ \\
Peak flow $(\mathrm{mL} / \mathrm{min})$ & $58.1 \pm 16.3$ & $101.5 \pm 35.6$ & $85.1 \pm 29.0$ \\
Minimum flow $(\mathrm{mL} / \mathrm{min})$ & $6.9 \pm 8.9$ & $-46.6 \pm 22.0 \dagger$ & $-10.5 \pm 8.1^{\ddagger}$ \\
Mean flow $(\mathrm{mL} / \mathrm{min})$ & $31.0 \pm 8.1$ & $14.0 \pm 2.9 \dagger$ & $21.1 \pm 2.7^{*}$ \\
Positive flow $(\mu \mathrm{L} / \mathrm{beat})$ & $223.7 \pm 66$ & $216.6 \pm 65.6$ & $165.7 \pm 31.1$ \\
Negative flow $(\mu \mathrm{L} /$ beat $)$ & $-0.2 \pm 0.6$ & $-114.8 \pm 58.9 \dagger$ & $-12.8 \pm 13.6^{\S}$
\end{tabular}

$P_{\text {Starling, }}$ Compression pressure in Starling flow resistor. Data are expressed as mean $\pm \mathrm{SD}$.

$* P<.01$ versus baseline.

$\dagger P<.0001$ versus baseline.

$\ddagger P<.01$ versus $\mathrm{P}_{\text {Starling }}=0$.

$\S P<.0001$ versus $\mathrm{P}_{\text {Starling }}=0$.

Table II. Changes of regional function

\begin{tabular}{lccc}
\hline & $\begin{array}{c}\text { Baseline } \\
\text { (normal) }\end{array}$ & $\begin{array}{c}\text { LV-LAD conduit } \\
\left(P_{\text {Starling }}=0 \text { mm Hg) }\right.\end{array}$ & $\begin{array}{c}\text { LV-LAD conduit } \\
\text { (maximum mean flow) }\end{array}$ \\
\hline P-SL area/EDL (mm Hg) & $13.5 \pm 4.8$ & $6.2 \pm 5.1$ & $9.2 \pm 5.0$ \\
Recovery ratio (\%) & 100 & $45.3 \pm 29.1^{*}$ & $70.2 \pm 27.8$ \\
\hline
\end{tabular}

$P$-SL area/EDL, Pressure-segment length area/end-diastolic length. $P_{\text {Starling }}$, compression pressure in Starling flow resistor. Recovery ratio is expressed as percent recovery compared with baseline value. Data are expressed as mean \pm SD.

$* P<.01$ versus baseline.

The organization that funded this research (Percardia Inc, Nashua, $\mathrm{NH}$ ) had no role in collection or interpretation of these data.

\section{Results}

Coronary flow and regional contractility. Blood flow through the conduit without flow regulation $\left(\mathrm{P}_{\text {Starling }}=0\right)$ peaked during midsystole and exhibited pandiastolic negative flow (Fig 2). Although the positive flow volume per beat was almost the same as under normal flow conditions, mean net forward blood flow through the conduit was significantly reduced because of the negative flow during diastole (Table I). The pressuresegment length loop after insertion of the LV-LAD conduit (Fig 3, A) was shifted to the right of the control loop, indicating a slight reduction in regional contractility.

When the Starling resistor was progressively pressurized, the negative diastolic blood flow decreased, whereas positive flow was only mildly affected (Fig 2, Table I). This was the case until $\mathrm{P}_{\text {Starling }}$ reached a critical point at which positive flow dropped precipitously (Fig 3, B, 4, A). On average, maximum mean conduit flow was achieved when $\mathrm{P}_{\text {Starling }}$ equaled $71.3 \% \pm 7.0 \%$ of peak LV pressure (range 65.3\%-83.5\%).

Coincident with the increase in mean coronary flow resulting from increases in $\mathrm{P}_{\text {Starling }}$, there was a corresponding leftward shift of the pressure-segment length loop (Fig 3, A), indicating that function improved as flow increased. Indeed, there was a roughly linear relationship between regional function and mean coronary flow as seen in Figs 3, $C$ (typical example) and 4, B (results from all studies). As a result, regional function, which was reduced to approximately $50 \%$ of baseline with $\mathrm{P}_{\text {Starling }}=0$, was restored to about $70 \%$ of baseline with optimal regulation of negative flow (Table II).

Regional blood flow. Regional blood flow in the LCx territory (control region) was roughly constant throughout the experiment (Fig 5). After establishment of the LV-LAD conduit with $\mathrm{P}_{\text {Starling }}=0 \mathrm{~mm} \mathrm{Hg}$, subendocardial blood flow in the LAD region was decreased. However, at the $\mathrm{P}_{\text {Starling }}$ that provided maximal mean LAD flow, subendocardial flow was significantly improved. Thus, it was speculated that changes in regional function during pressurization of the Starling resistor would correlate with changes in subendocardial blood flow. This was confirmed (Fig 6) by correlating subendocardial flow and regional function $\left(\mathrm{r}^{2}=.54, P=.0041\right)$.

Postischemic reactive hyperemia. Representative tracings of coronary flow and a summary of the results from 6 dogs after 2-minute LAD occlusions are shown before (Fig 7, $A$ and $C$ ) and after (Fig 7, $B$ and $D$ ) creation of the LV-LAD conduit, respectively. During normal perfusion, maximum mean hyperemic LAD flow 

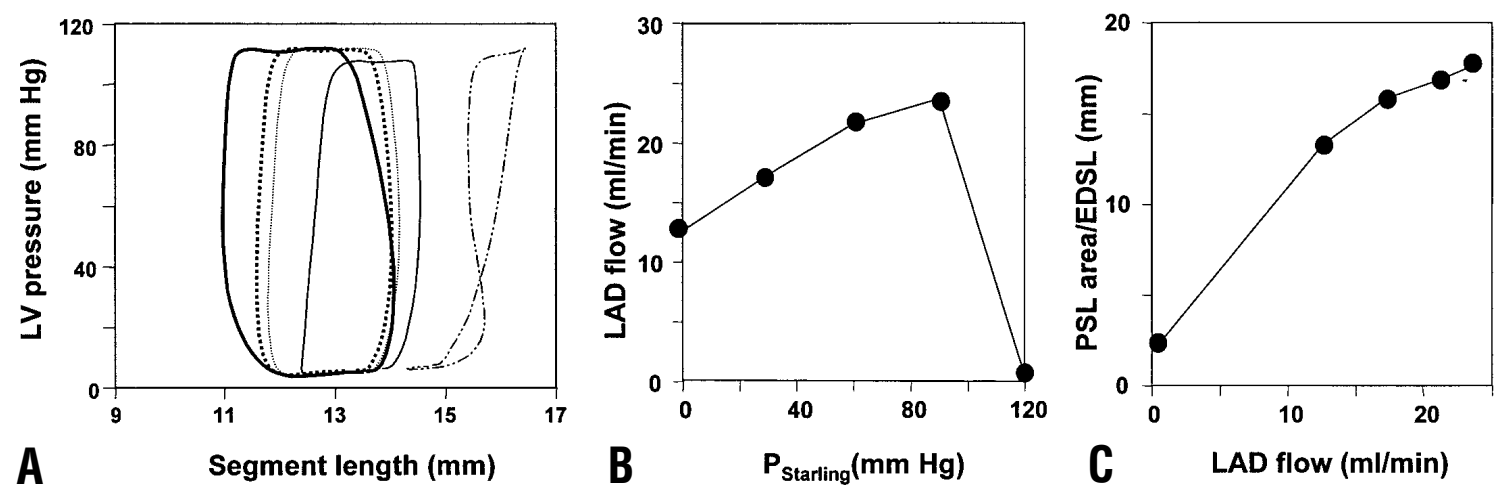

Fig 3. A, Representative left ventricular pressure-segment length loops. Thick solid line, baseline; thin solid line, $\mathrm{P}_{\text {Starling }}=0 ;$ dotted line, $\mathrm{P}_{\text {Starling }}=60 \mathrm{~mm} \mathrm{Hg} ;$ dashed line, $\mathrm{P}_{\text {Starling }}=90 \mathrm{~mm} \mathrm{Hg} ;$ dashed-dotted line, $\mathrm{P}_{\text {Starling }}=120$ $\mathrm{mm} \mathrm{Hg}$. B, The relation between $\mathrm{P}_{\text {Starling }}$ and mean left anterior descending flow. $\mathbf{C}$, Relation between mean coronary flow and regional function assessed by pressure-segment length area/end-diastolic segment length (PSL area/EDSL). $P_{\text {Starling, }}$ The compression pressure in the Starling flow resistor; $L V$, left ventricular; $L A D$, left anterior descending coronary artery.
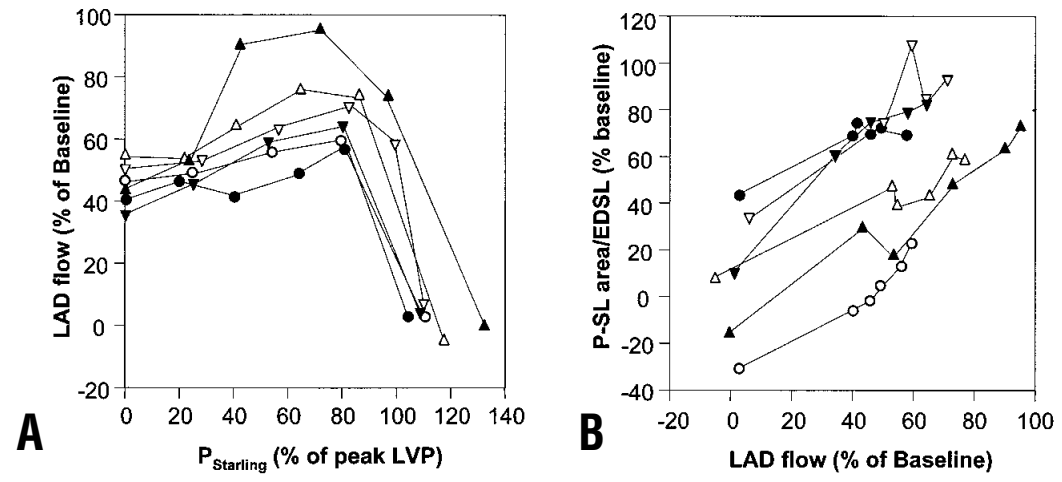

Fig 4. A, Relationship between $P_{\text {Starling }}$ and mean LAD flow. B, Relationship between the pressure-segment length area/end-diastolic segment length $(P-S L$ area/EDSL) and mean LAD flow through the LV-LAD conduit. See Fig 3 for abbreviations.

reached $389 \% \pm 78 \%(296 \%-467 \%)$ of mean baseline LAD flow at $9.8 \pm 2.9$ seconds (6-12 seconds) after release of the occlusion. After LV-LAD conduit placement, however, peak, minimum, and mean LAD flows attained their steady state values within $14.3 \pm 6.7 \mathrm{sec}-$ onds (6-21 seconds) after release of the occlusion. The lack of a hyperemic response indicates that the bed is prevasodilated in the presence of the LV-LAD conduit.

Coronary flow and functional reserve during atrial pacing. Changes in mean LAD flow and regional function in each of 3 dogs studied at different heart rates are shown in Fig 8. In all hearts with natural flow through the LAD, mean coronary flow was mildly increased as heart rate was increased from 100 to 140 $\mathrm{min}^{-1}$. Regional function was relatively well maintained until heart rate reached $160 \mathrm{~min}^{-1}$.
In the presence of the LV-LAD conduit without flow regulation, mean LAD flow was maintained roughly constant at heart rates between 100 and $160 \mathrm{~min}^{-1}$. In terms of the function with the LV-LAD conduit, there was a uniform mild decrease as heart rate increased.

"Double conduit" and global LV function. Typical pressure-volume loops obtained under baseline conditions, with a single LAD conduit, and after addition of the second conduit to the LCx are shown in Fig 9. The ESPVR changed little with the single conduit but shifted downward with the double conduit. The parameters of the ESPVRs along with other hemodynamic parameters under these conditions from the 3 animals studied are summarized in Table III. Analysis of covariance revealed a consistent downward shift of the ESPVR compared with baseline with both conduits in place. 

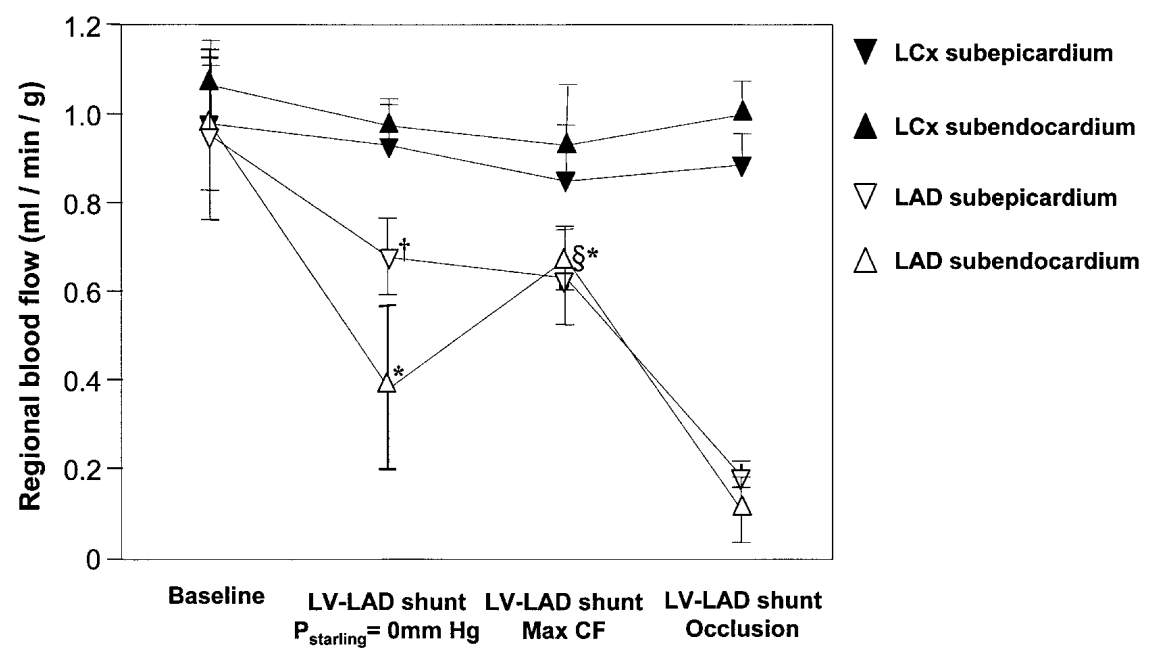

$\triangle$ LAD subendocardium

Fig 5. Relationship between subepicardial and subendocardial blood flow and $\mathrm{P}_{\text {Starling }}$ in the territory of the circumflex coronary artery $(L C x)$ and left anterior descending coronary artery $(L A D)$. $L V$, Left ventricle; $\operatorname{Max} C V$, maximum coronary flow. $* P<.001$ versus baseline; $\dagger P<.005$ versus $\mathrm{P}_{\text {Starling }}=0 \mathrm{~mm} \mathrm{Hg}$.

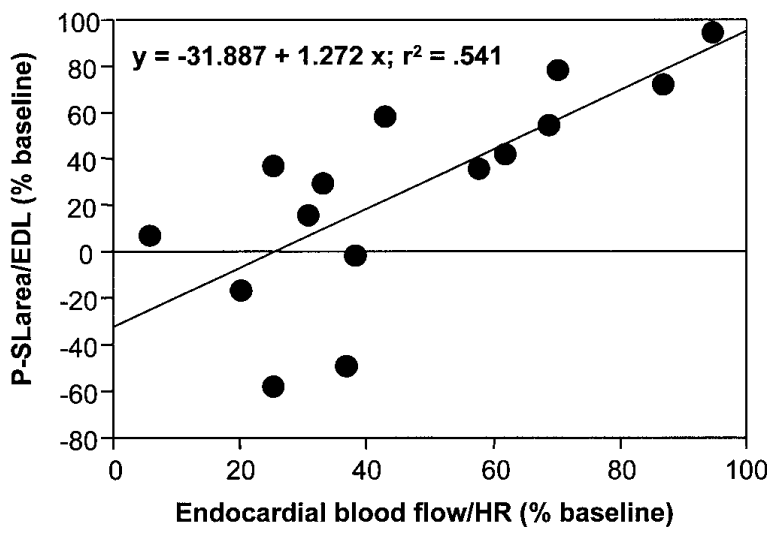

Fig 6. Relation between P-SL area/EDSL and normalized subendocardial blood flow. Subendocardial flow was divided by heart rate and then normalized. See Fig 3 for abbreviations.

When both shunts were occluded, global function deteriorated significantly within a few beats, aortic pressure decreased, and ventricular fibrillation developed relatively quickly. This confirms that blood flow through these conduits was indeed supporting myocardial function to an extent that global function and hemodynamics could be maintained.

\section{Discussion}

Use of an LV-LAD conduit without flow regulation was able to provide approximately $45 \%$ of normal net forward flow while maintaining regional function at about $45 \%$ of its normal value, both markedly improved compared with conditions with a totally occluded vessel. Control of backward coronary flow further improved net forward flow and regional function, each increasing to approximately $70 \%$ of their normal values.

The physiology of LV-LAD conduits has been examined in two prior studies with conflicting results. Munro and Allen ${ }^{1}$ reported a reduction of about $70 \%$ in net forward flow followed by a significant fall in aortic pressure and myocardial contractility using a plastic cannula connecting the proximal LAD to the LV. More recently, Tweden and associates ${ }^{2}$ implanted a rigid L-shaped titanium cannula in pigs and reported that net forward flow was maintained at approximately $76 \%$ of baseline.

In our studies, mean total and subendocardial coronary flow ranged between $35.8 \%-54.2 \%$ and $25.0 \%$ $38.0 \%$, respectively, without flow regulation. It has been shown that either 30\%-40\% of normal transmural flow or 20\%-30\% of normal subendocardial blood flow is critical for maintaining systolic function. ${ }^{8}$ Consistent with these prior studies, with relatively wide overall ranges of total and subendocardial blood flows observed without regulation of negative flow (ie, with $\mathrm{P}_{\text {Starling }}=0$ ), we also observed a wide range of functional preservation, ranging from $-1.8 \%$ (akinesis) to $74 \%$ of baseline.

No significant coronary flow reserve was observed during use of the LV-LAD conduit at $\mathrm{P}_{\text {Starling }}=0$ as evi- 


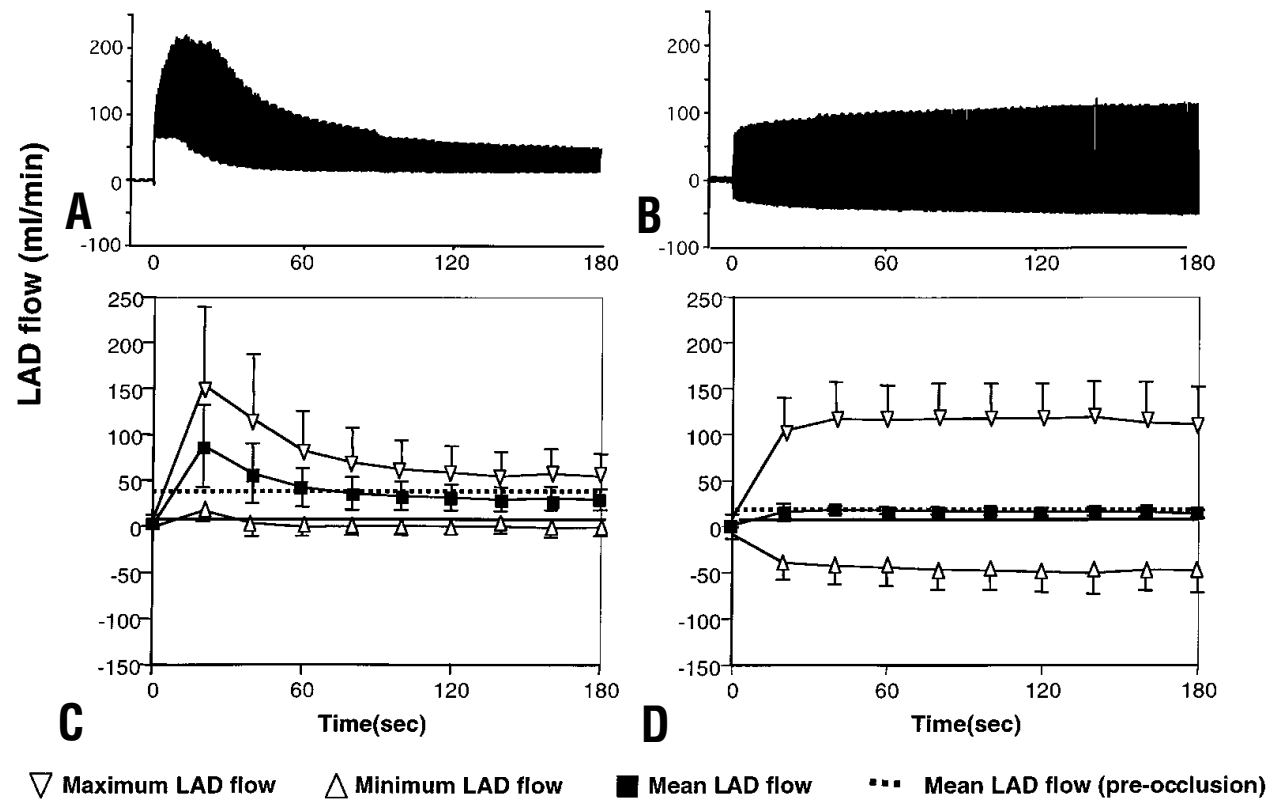

Fig 7. Representative tracings of reactive hyperemic flow and mean LAD flow after release of a 2-minute LAD occlusion before (A and $\mathbf{C}$, respectively) and after (B and D, respectively) establishing an LV-LAD conduit with $\mathrm{P}_{\text {Starling }}=0$. See Fig 3 for abbreviations.

Table III. Global cardiac function and coronary flow with LV-coronary conduit $(n=3)$

\begin{tabular}{|c|c|c|c|}
\hline & Control & Single conduit & Double conduit \\
\hline Peak LV pressure (mm Hg) & $118.2 \pm 5.5$ & $104.7 \pm 8.9$ & $94.0 \pm 13.8$ \\
\hline Ees $(\mathrm{mm} \mathrm{Hg})$ & $6.4 \pm 1.6$ & $4.8 \pm 3.5$ & $3.1 \pm 2.9^{*}$ \\
\hline $\mathrm{V}_{0}(\mathrm{~mL})$ & $1.5 \pm 9.8$ & $-12.2 \pm 30.5$ & $-0.5 \pm 9.0^{*}$ \\
\hline Ejection fraction (\%) & $66.2 \pm 9.1$ & $40.1 \pm 17.7$ & $40.6 \pm 23.6$ \\
\hline Mean LAD flow (mL/min) & $30.9 \pm 12.5$ & $12.1 \pm 8.5$ & $12.1 \pm 2.5$ \\
\hline Mean LCx flow (mL/min) & $40.7 \pm 8.3$ & $37.8 \pm 9.6$ & $19.5 \pm 2.7$ \\
\hline
\end{tabular}

$L V$, Left ventricular; Ees, end-systolic pressure-volume relation; $V_{0}$, volume intercept; $L A D$, left anterior descending coronary artery; $L C x$, left circumflex coronary artery.

$* P<.05$ versus end-systolic pressure-volume relationship at baseline by analysis of covariance.

denced by lack of a reactive hyperemic response or increase in blood flow with increased heart rate. This suggests that under these conditions, the vascular bed is relatively underperfused and there is a pre-existent vasodilation.

Although normal regional and global function was not fully maintained with either the single or double conduits, the coronary flow through these conduits was physiologically important and significantly better than what was observed with no flow when the shunts were occluded.

Significance of LV-coronary conduits in clinical settings. The number of redo coronary artery bypass operations accounts for nearly $20 \%$ of all coronary revascularization procedures. ${ }^{9,10}$ This population tends to be older and sicker, the ascending aorta may be calcified, and performing multiple proximal anastomoses can be problematic. The number of available conduits may also be limited. ${ }^{11}$ Thus, the surgical challenges associated with redo operations makes desirable the availability of alternative revascularization techniques implementable by minimally invasive approaches, preferably without cardiopulmonary bypass. Availability of a clinically applicable LV-coronary conduit that would maintain patency could overcome some of these hurdles. Such conduits could be implanted via a limited thoracotomy because the procedure requires only a small area surrounding the target vessel. 

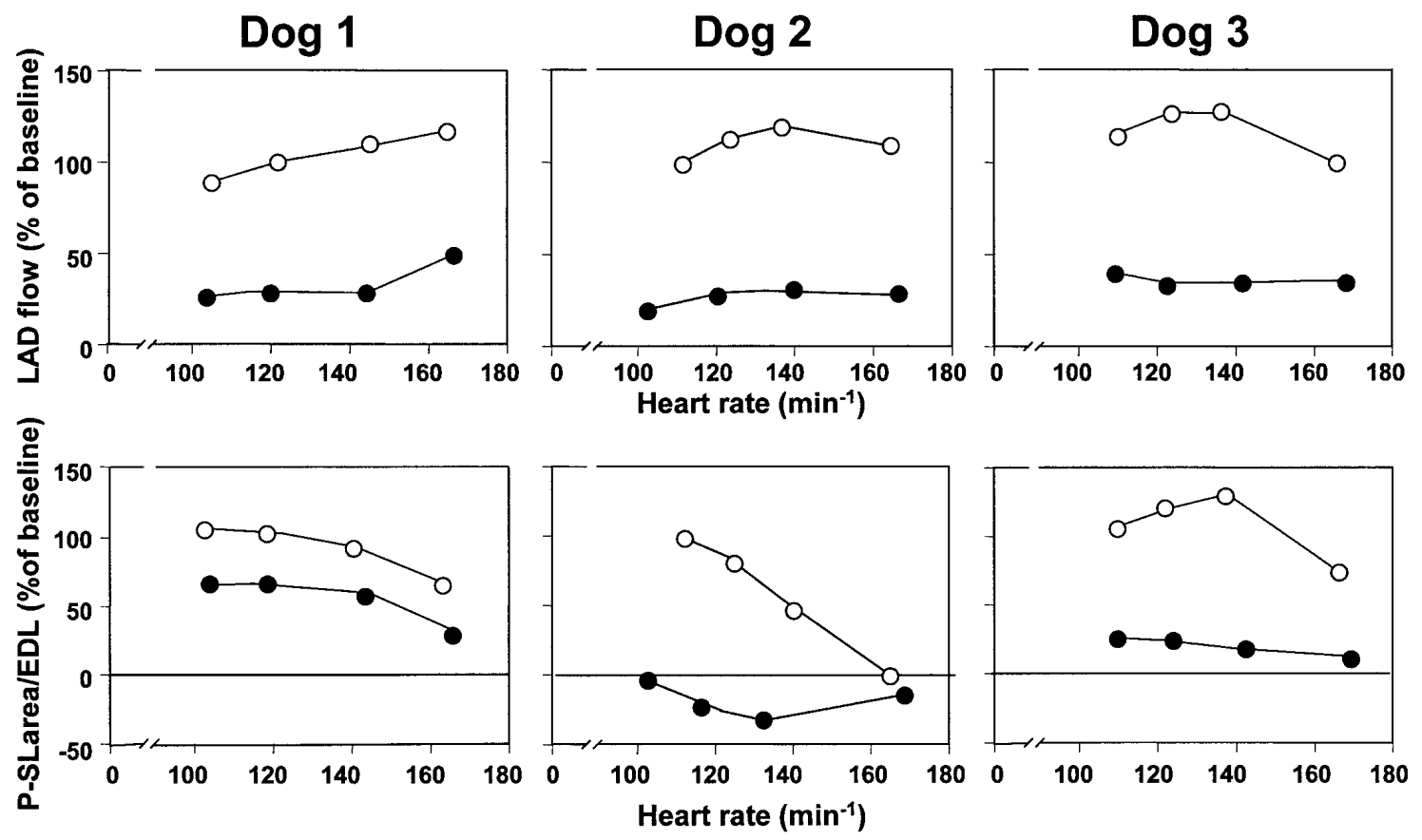

Fig 8. Changes of mean LAD flow and P-SL/EDSL during atrial pacing in 3 dogs before (upper panels) and after (bottom panels) placement of the LV-LAD shunt. P-SL area/EDL, Pressure-segment length area/end-diastolic length; $L A D$, left anterior descending coronary artery.

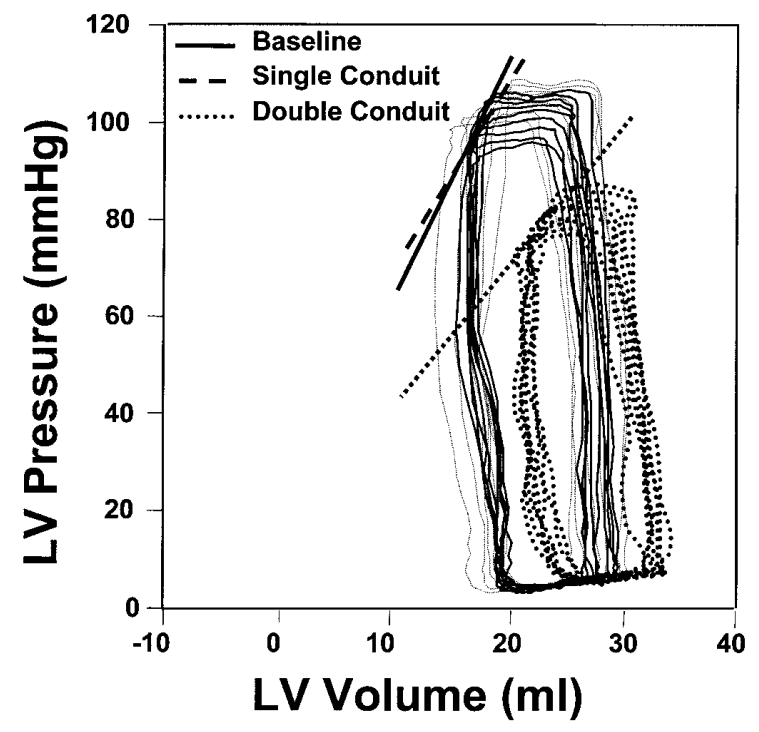

Fig 9. Example of pressure-volume loops and ESPVRs obtained in the double conduit experiments. Relations and loops obtained in this example are similar under baseline and single conduit conditions. With addition of the second conduit, global function is maintained at about half of the baseline condition. See Table III for details of how double hemodynamics are influenced in the double conduit experiment. $L V$, Left ventricular.
Furthermore, as in the current study, the procedure can be carried out without cardiopulmonary bypass with myocardial ischemic times less than 2 minutes. Another possible application could be for circumstances requiring rapid intraoperative restoration of flow such as emergency procedures after coronary occlusions following interventional procedures (angioplasty) or, as sometimes may occur, with intraoperative compromise of the coronary circulation.

Although normal flow was not achieved with the nonoptimized conduit used in the present study, it markedly improved myocardial perfusion and regional function compared with those of a vessel that was totally occluded. As reported by numerous investigators, revascularization of totally occluded vessels in regions of retained myocardial viability improves regional/ global function and symptoms. ${ }^{12,13}$ Thus, especially in the patients with multivessel disease who lack available grafts, more complete revascularization could be achieved through the use of LV-coronary conduits.

\section{Limitations}

Dogs have significant pre-existent collateral coronary circulation. ${ }^{14-16}$ Therefore, it could be argued that collateral flow could have accounted for a significant amount 
of regional flow and function observed after LV-LAD conduit implantation. Experimentally, any visible epicardial collateral vessels were ligated. Furthermore, three pieces of data ensure that this was not the case. First, on occlusion of the LV-LAD conduit, regional function deteriorated profoundly (eg, Figs 2 to 4), indicating that any existing collateral flow was unable to maintain regional function. Second, direct measurement of regional blood flow by means of microspheres (Fig 5) showed that both epicardial and endocardial blood flow dropped to near 0 on conduit occlusion. Third, in the double conduit experiment, all vascular supply is directly from the LV, and the fact that global function could be maintained to approximately $50 \%$ of normal (essentially the same as regional function in the single conduit experiment) indicates the lack of reliance on collateral flow. These findings indicate that the results were not influenced by the presence of collateral flow. On the other hand, because collateral vessels were ligated, we could not address whether an LV-LAD shunt used in the presence of significant collateral flow could create a steal phenomenon and induce ischemia in the source bed of the collateral blood. This is an important issue because many patients undergoing bypass surgery have collateral flow to ischemic beds.

\section{Conclusions}

An LV-coronary artery conduit can provide about $45 \%$ of normal regional coronary flow and function. Incorporation of a flow regulation to minimize backward flow during diastole significantly increases both parameters. Because this LV-coronary conduit significantly improves coronary flow compared with that of a totally or subtotally occluded vessel, this approach could be useful clinically for achieving a more complete degree of revascularization in cases of complicated coronary bypass if a clinically applicable device that maintains patency long term could be developed. It is also possible that a better engineered conduit with more favorable forward than backward flow characteristics could be designed to provide greater net forward flow.

\section{REFERENCES}

1. Munro I, Allen P. The possibility of myocardial revascularization by creation of a left ventriculocoronary artery fistula. $\mathrm{J}$ Thorac Cardiovasc Surg 1969;58:25-32.
2. Tweden KS, Eales F, Cameron JD, Griffin JC, Solien EE, Knudson MB. Ventriculocoronary artery bypass (VCAB), a novel approach to myocardial revascularization. Heart Forum 2000;3:1-8.

3. Patterson SW, Starling EH. On the mechanical factors which determine the output of the ventricles. J Physiol 1914;48:357-79.

4. Kowallik P, Schulz R, Guth BD, Schade A, Paffhausen W, Gross $\mathrm{R}$, et al. Measurement of regional myocardial blood flow with multiple colored microspheres. Circulation 1991;83:974-82.

5. Baan J, van der Velde ET, de Bruin HG, Smeenk GJ, Koops J, van Dijk AD, et al. Continuous measurement of left ventricular volume in animals and humans by conductance catheter. Circulation 1984;70:812-23.

6. Lankford EB, Kass DA, Maughan WL, Shoukas AA. Does volume catheter parallel conductance vary during a cardiac cycle? Am J Physiol 1990;258:H1933-42.

7. Kass DA, Yamazaki T, Burkhoff D, Maughan WL, Sagawa K. Determination of left ventricular end-systolic pressure-volume relationships by the conductance (volume) catheter technique. Circulation 1986;73:586-95.

8. Gallagher KP, Matsuzaki M, Koziol JA, Kemper WS, Ross J Jr. Regional myocardial perfusion and wall thickening during ischemia in conscious dogs. Am J Physiol 1984;247:H727-38.

9. Cosgrove DM, Loop FD, Lytle BW, Gill CC, Golding LA, Gibson C, et al. Predictors of reoperation after myocardial revascularization. J Thorac Cardiovasc Surg 1986;92:811-21.

10. Stephan WJ, O'Keefe JH Jr, Piehler JM, McCallister BD, Dahiya RS, Shimshak TM, et al. Coronary angioplasty versus repeat coronary artery bypass grafting for patients with previous bypass surgery. J Am Coll Cardiol 1996;28:1140-6.

11. Reardon MJ, Conklin LD, Reardon PR, Baldwin JC. Coronary artery bypass conduits: review of current status. J Cardiovasc Surg (Torino) 1997;38:201-9.

12. Vanoverschelde JL, Wijns W, Depre C, Essamri B, Heyndrickx GR, Borgers M, et al. Mechanisms of chronic regional postischemic dysfunction in humans: new insights from the study of noninfarcted collateral-dependent myocardium [see comments]. Circulation 1993;87:1513-23.

13. Pocock SJ, Henderson RA, Seed P, Treasure T, Hampton JR. Quality of life, employment status, and anginal symptoms after coronary angioplasty or bypass surgery: 3-year follow-up in the Randomized Intervention Treatment of Angina (RITA) Trial. Circulation 1996;94:135-42.

14. Schaper W, Binz K, Saas S, Winkler B. Influence of collateral blood flow and of variations in MVO2 on tissue-ATP content in ischemic and infarcted myocardium. J Mol Cell Cardiol 1987;19:19-37.

15. Jugdutt BI, Becker LC, Hutchins GM. Early changes in collateral blood flow during myocardial infarction in conscious dogs. Am J Physiol 1979;237:H371-80.

16. Kanazawa T. Coronary collateral circulation-its development and function. Jpn Circ J 1994;58:151-65. 